\title{
Edge - Odd Gracefulness of Few Fan Graph Merging a Finite Number of Circuits and a Star
}

\author{
K. Thirusangu \\ Associate Professor of \\ Mathematics, \\ SIVET College, \\ Gowrivakkam, Chennai
}

\author{
P. Nedumaran \\ Assistant Professor of \\ Mathematics, \\ Gurunanak College, \\ Velacherry, Chennai
}

\author{
A. Solairaju \\ Associate Professor of \\ Mathematics, \\ Jamal Mohamed College, \\ Tiruchirappalli, Tamilnadu, \\ India
}

\begin{abstract}
The Friendship graphs $\mathrm{F}\left(\mathrm{nC}_{3} * \mathrm{~S}_{\mathrm{k}}\right), \mathrm{F}\left(\mathrm{nC}_{5} * \mathrm{~S}_{\mathrm{k}}\right)$ and $\mathrm{F}\left(2 \mathrm{nC}_{3} *\right.$ $S_{k}$ ) are all even vertex graceful where $n$ is a positive integer.
\end{abstract}

\section{Keywords}

Friendship graphs, Star, Circuits

\section{INTRODUCTION}

A.Solairaju, and A.Sasikala [2008] got gracefulness of a spanning tree of the graph of product of $\mathrm{P}_{m}$ and $\mathrm{C}_{\mathrm{n}}$, A.Solairaju and K.Chitra [2009] obtained edge-odd graceful labeling of some graphs related to paths. A.Solairaju, and C. Vimala [2008] gracefulness of a spanning tree of the graph of Cartesian product of $S_{m}$ and $S_{n}$

A.Solairaju and P.Muruganantham [2009] proved that ladder $\mathrm{P}_{2} \times \mathrm{P}_{\mathrm{n}}$ is even-edge graceful (even vertex graceful). They found [2010] the connected graphs $\mathrm{P}_{\mathrm{n}} \mathrm{o} \mathrm{nC}_{3}$ and $\mathrm{P}_{\mathrm{n}} \mathrm{O} \mathrm{nC}_{7}$ are both even vertex graceful, where $\mathrm{n}$ is any positive integer. They also obtained [2010] that the connected graph $\mathrm{P}_{\mathrm{n}} \Delta \mathrm{nC}_{4}$ is even vertex graceful, where $\mathrm{n}$ is any even positive integer.

\section{Section I - Preliminaries and definitions:}

The following definitions are now given:

Definition 1.1: Let $G=(V, E)$ be a simple graph with $p$ vertices and $\mathrm{q}$ edges. A map

$: \mathrm{V}(\mathrm{G}) \rightarrow\{0,1,2, \ldots, \mathrm{q}\}$ is called a graceful labeling if $\mathrm{f}$ is one to - one; The edges receive all the labels (numbers) from 1 to $\mathrm{q}$ where the label of an edge is the absolute value of the difference between the vertex labels at its ends. A graph having a graceful labeling is called a graceful graph.

\section{Definition 1.2}

A graph is odd-edge graceful if there exists an injective map $\mathrm{f}: \mathrm{E}(\mathrm{G}) \rightarrow\{1,3,5, \ldots, 2 \mathrm{q}\}$ so that the induced map $\mathrm{f}+\mathrm{V}(\mathrm{G})$ $\rightarrow\{0,1,2,3, \ldots, 2 \mathrm{k}-2\}$ defined by $\mathrm{f}+(\mathrm{x})=\sum \mathrm{f}(\mathrm{xy})(\bmod 2 \mathrm{k})$ where $\mathrm{k}=\max \{\mathrm{p}, \mathrm{q}\}$ makes all distinct.

\section{Example 1.3}

The following connected graph is edge-odd graceful.

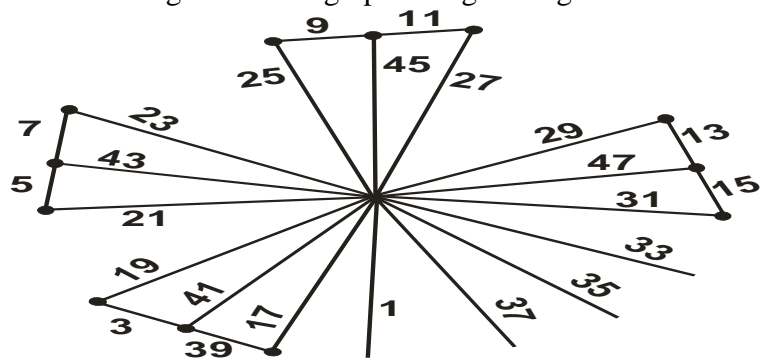

\section{Definition 1.4}

A friendship graph or a fan graph $\mathrm{F}(\mathrm{nC} 3 * \mathrm{Sk})$ is defined as the following connected graph containing $\mathrm{n}$ copies of circuits of each length 3 with some arbitrary labeling of edges in

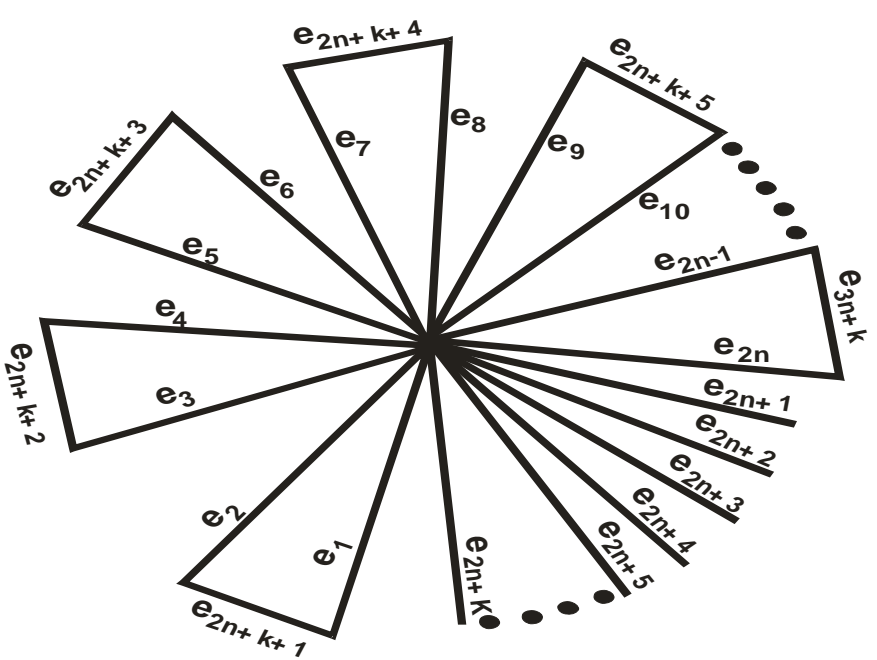

Figure 1: Friendship graph $\mathrm{F}\left(\mathrm{nC}_{3}\right)$ with some arbitrary labelings for edges

\section{NEW CLASSES OF EDGE-ODD \\ GRACEFUL GRAPHS}

The discussion is started with the following theorem:

\section{Theorem 2.1}

The friendship graph $\mathrm{F}(\mathrm{nC} 3 * \mathrm{Sk})$ is edge-odd graceful where $\mathrm{n} \equiv 0(\bmod 3)$

\section{Proof}

The graph $\mathrm{F}(\mathrm{nC} 3 * \mathrm{Sk})$ has vertex set $\{\mathrm{V} 0, \mathrm{~V} 1, \mathrm{~V} 2, \mathrm{~V} 3, \mathrm{~V} 4$, $\ldots, V 2 n-1, V 2 n, V 2 n+1, V 2 n+2, \ldots, V 2 n+k\}$. It has edge set $\{$ ei $=$ V0Vi: $i$ varies from 1 to $n\} \cup\{$ e $2 n+k+i=V i V i+1: i$ varies from $1,3,5, \ldots, 2 \mathrm{n}-1\} \cup\{\mathrm{e} 2 \mathrm{n}+\mathrm{i}=\mathrm{V} 0 \mathrm{Vi}$ : $\mathrm{i}$ varies from $2 \mathrm{n}+1,2 \mathrm{n}+2, \ldots, 2 \mathrm{n}+\mathrm{k}\}$.

Define $\mathrm{f}: \mathrm{E}(\mathrm{G}) \rightarrow\{1,3,5, \ldots 2 \mathrm{q}-1\}$,by $\mathrm{f}(\mathrm{e} i)=2 \mathrm{i}-1 \quad$ ( $\mathrm{i}=1$ to $3 \mathrm{n}+\mathrm{k} ; \mathrm{I} \neq 2 \mathrm{n}+\mathrm{k}, \mathrm{i} \neq 2 \mathrm{n}+\mathrm{k}+1)$

$\mathrm{f}(\mathrm{e} 2 \mathrm{n}+\mathrm{k})=(4 \mathrm{n}+2 \mathrm{k}-1) ; \mathrm{f}(\mathrm{e} 2 \mathrm{n}+\mathrm{k}+1)=(4 \mathrm{n}+2 \mathrm{k}+1)($ if $\mathrm{k} \geq$ n)

$\mathrm{f}(\mathrm{e} 2 \mathrm{n}+\mathrm{k})=(4 \mathrm{n}+2 \mathrm{k}+1) ; \mathrm{f}(\mathrm{e} 2 \mathrm{n}+\mathrm{k}+1)=(4 \mathrm{n}+2 \mathrm{k}-1)($ if $\mathrm{k}<$ n).

Then the induced map $f+(u)=\sum f(u v) \quad(\bmod 2 q)$ where the sum runs over all edges uv through $v$. Now, $f$ and $f+$ both 
satisfy edge-odd graceful labeling. Thus the connected graph $\mathrm{F}(\mathrm{nC} 3 * \mathrm{Sk})$ is an edge-odd graceful.

Example 2.2: The friendship graph $\mathrm{F}(6 \mathrm{C} 3 * \mathrm{~S} 2)$ is edgeodd graceful.

The graph has $\mathrm{p}$ $=15$ vertices, $\mathrm{q}=20$ edges. The edge-odd graceful labelings are mentioned below in figure 2 :

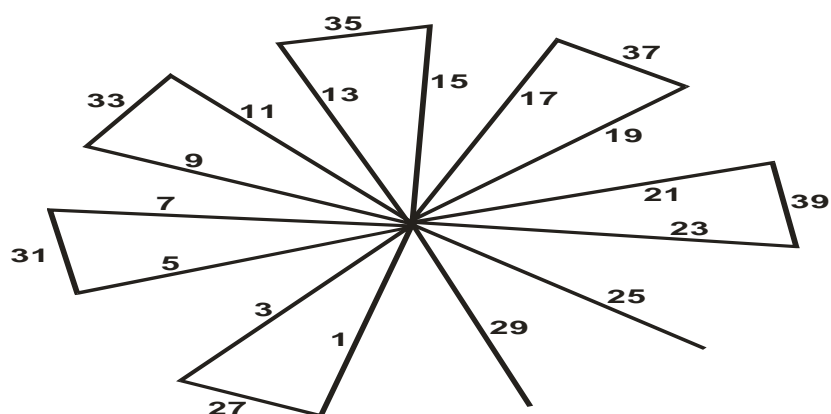

Figure 2: Edge-odd graceful of the friendship graph $\mathrm{F}\left(6 \mathrm{C}_{3}\right.$ $* \mathbf{S}_{2}$ )

Theorem 2.2 The friendship graph $\mathrm{F}(\mathrm{nC} 3 * \mathrm{Sk})$ is edgeodd graceful where $n \equiv 1(\bmod 3)$

Proof: The graph $\mathrm{F}(\mathrm{nC} 3 * \mathrm{Sk})$ has vertex set $\{\mathrm{V} 0, \mathrm{~V} 1, \mathrm{~V} 2$, $\mathrm{V} 3, \mathrm{~V} 4, \ldots, \mathrm{V} 2 \mathrm{n}-1, \mathrm{~V} 2 \mathrm{n}, \mathrm{V} 2 \mathrm{n}+1, \mathrm{~V} 2 \mathrm{n}+2, \ldots, \mathrm{V} 2 \mathrm{n}+\mathrm{k}\}$. It has edge set $\{$ ei $=V 0 V n+k+i$ i varies from 1 to $2 n\} \cup\{$ ei $=$ $\mathrm{ViVi}+1$ : i varies from $1,3,5, \ldots, 2 \mathrm{n}-1\} \cup\{\mathrm{e} 2 \mathrm{n}+\mathrm{i}=\mathrm{V} 0 \mathrm{Vi}: \mathrm{i}$ varies from $2 \mathrm{n}+1,2 \mathrm{n}+2, \ldots, 2 \mathrm{n}+\mathrm{k}\}$. The other arbitrary labelings od edges for the graph $\mathrm{F}(\mathrm{nC} 3 * \mathrm{Sk})$ are as follows:

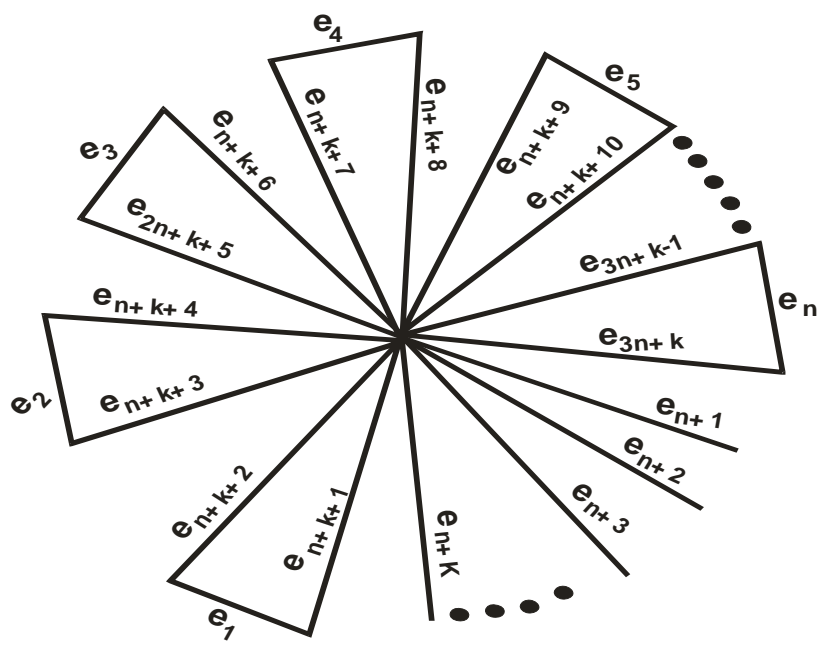

Figure 3: Arbitrary labelings of the friendship graph $\mathbf{F}\left(\mathbf{n C}_{\mathbf{3}} * \mathbf{S}_{\mathrm{k}}\right)$

To get the required edge-odd graceful labelings, define $\mathrm{f}$ : $\mathrm{E}(\mathrm{G}) \rightarrow\{1,3,5, \ldots 2 \mathrm{q}-1\}$, by $\mathrm{f}(\mathrm{ei})=(2 \mathrm{i}-1), \mathrm{i}=1$ to $(3 \mathrm{n}+\mathrm{k})$.

Then the induced map $f+(u)=\sum f(u v) \quad(\bmod 2 q)$ where the sum runs over all edges uv through $v$. Now, $f$ and $f+$ both satisfy edge-odd graceful labeling. Thus the connected graph $\mathrm{F}(\mathrm{nC} 3 * \mathrm{Sk})$ is an edge-odd graceful.

Example 2.4: The friendship graph $\mathrm{F}(7 \mathrm{C} 3 * \mathrm{~S} 4)$ is edgeodd graceful

The graph has $\mathrm{p}=19$ vertices, $\mathrm{q}=25$ edges. The edge-odd graceful labelings are mentioned below:

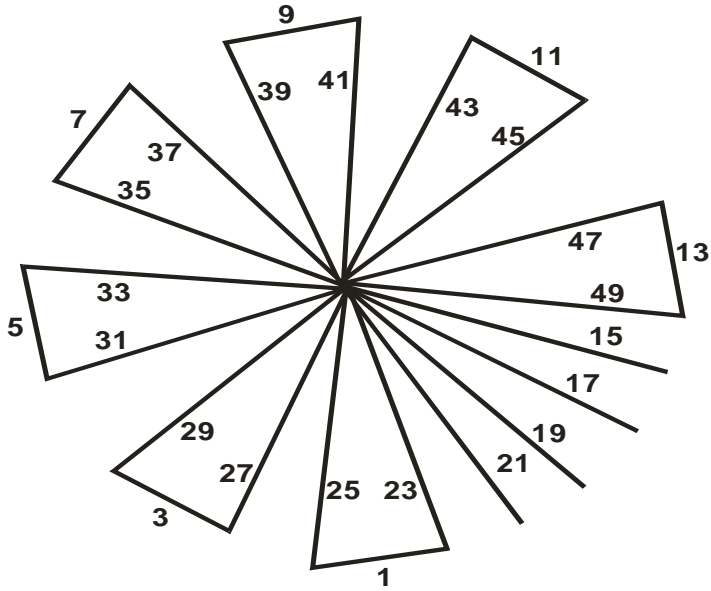

Figure 4: Edge-odd graceful of the friendship graph $\mathrm{F}\left(\mathrm{7C}_{3}\right.$ $\left.* \mathbf{S}_{4}\right)$

Theorem 2.5: The friendship graph $\mathrm{F}\left(\mathrm{nC}_{3} * \mathrm{~S}_{\mathrm{k}}\right)$ is edgeodd graceful where $\mathrm{n} \equiv 2(\bmod 3)$ Proof: The graph $\mathrm{F}\left(\mathrm{nC}_{3} *\right.$ $S_{k}$ ) has vertex set $\left\{V_{0}, V_{1}, V_{2}, V_{3}, V_{4}, \ldots, V_{2 n-1}, V_{2 n}, V_{2 n+1}\right.$, $\left.\mathrm{V}_{2 \mathrm{n}+2}, \ldots, \mathrm{V}_{2 \mathrm{n}+\mathrm{k}}\right\}$. It has edge set $\left\{\mathrm{e}_{1+3(\mathrm{i}-1) / 2}=\mathrm{V}_{0} \mathrm{~V}_{\mathrm{i}}\right.$ : $\mathrm{i}$ varies from $1,3,5, \ldots$, to $2 \mathrm{n}-1\} \cup\left\{\mathrm{e}_{3 \mathrm{i} / 12}=\mathrm{V}_{0} \mathrm{~V}_{\mathrm{i}}\right.$ : $\mathrm{i}$ varies from $2,4,6, \ldots$, to $2 \mathrm{n}\} \cup\left\{\mathrm{e}_{2+3(\mathrm{i}-1) / 2}=\mathrm{V}_{\mathrm{i}} \mathrm{V}_{\mathrm{i}+1}: \mathrm{i}\right.$ varies from $1,3,5$, $\ldots, 2 n-1\} \cup\left\{e_{2 n+i}=V_{0} V_{i}: i\right.$ varies from $2 n+1,2 n+2, \ldots, 2 n$ $+\mathrm{k}\}$.

The third arbitrary labelings of the edges for the graph $\mathrm{F}\left(\mathrm{nC}_{3}\right.$ * $\mathrm{S}_{\mathrm{k}}$ ) are as follows:

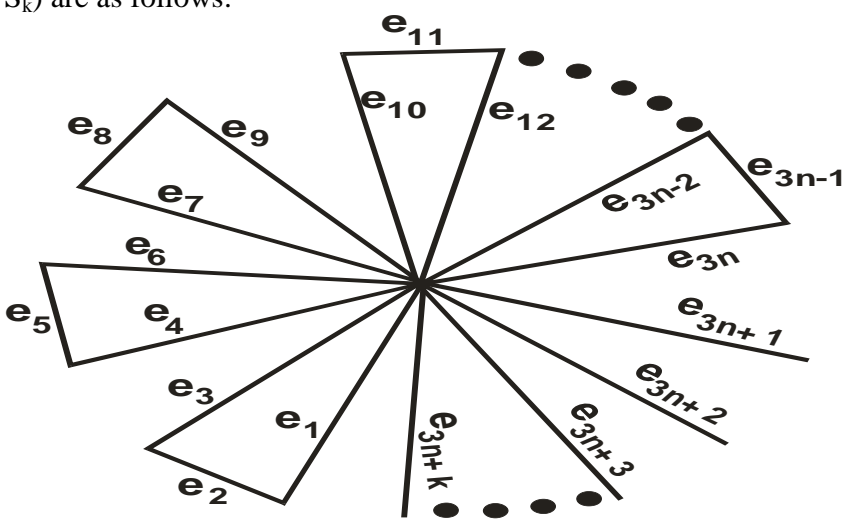

Figure 5: An arbitrary labelings of the friendship graph $\mathbf{F}\left(\mathrm{nC}_{3} * \mathbf{S}_{\mathrm{k}}\right)$

To get edge-odd graceful labelings in this cases, Define $\mathrm{f}$ : $\mathrm{E}(\mathrm{G}) \rightarrow\{1,3,5, \ldots 2 \mathrm{q}-1\}$, by $\quad \mathrm{f}\left(\mathrm{e}_{\mathrm{i}}\right)=(2 \mathrm{i}-1), \mathrm{i}=1$ to $3 n+k, i \neq 3 n-2, i \neq 3 n-1 ; f\left(e_{3 n-2}\right)=6 n-3, f\left(e_{3 n-1}\right)=6 n-5$ if $k$ $<\mathrm{n} ; \quad \mathrm{f}\left(\mathrm{e}_{3 \mathrm{n}-2}\right)=6 \mathrm{n}-5, \mathrm{f}\left(\mathrm{e}_{3 \mathrm{n}-1}\right)=6 \mathrm{n}-3$ if $\mathrm{k} \geq \mathrm{n}$.

Then the induced map $\mathrm{f}^{+}(\mathrm{u})=\sum \mathrm{f}(\mathrm{uv}) \quad(\bmod 2 \mathrm{q})$ where the sum runs over all edges uv through $v$. Now, $f$ and $\mathrm{f}^{+}$both satisfy edge-odd graceful labeling. Thus the connected graph $\mathrm{F}\left(\mathrm{nC}_{3} * \mathrm{~S}_{\mathrm{k}}\right)$ is an edge-odd graceful.

Example 2.5: The friendship graph $\mathrm{F}\left(5 \mathrm{C}_{3} * \mathrm{~S}_{4}\right)$ is edgeodd graceful

The graph has $p=14$ vertices, $q=19$ edges. The edge-odd graceful labelings are mentioned below: 


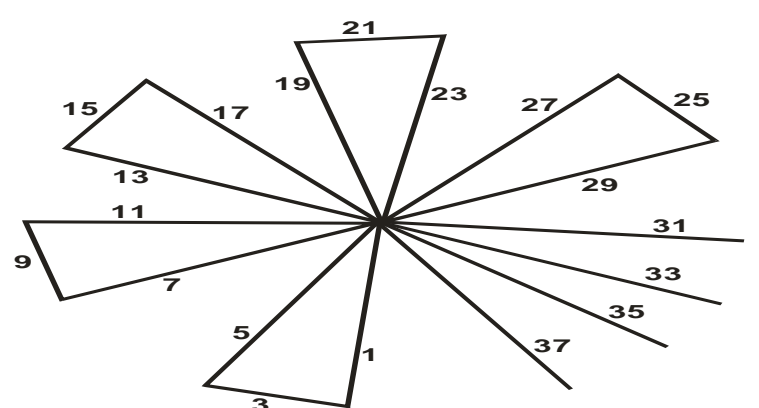

Figure 6: Edge-odd graceful of the friendship graph $\mathrm{F}\left(\mathrm{5C}_{3}\right.$ $\left.* \mathbf{S}_{4}\right)$

\section{DIFFERENT TYPES OF FRIENDSHIP GRAPHS HAVING EDGE-ODD GRACEFUL LABELINGS}

The following is now to be verified:

Theorem 3.1: The friendship graph $\mathrm{F}\left(\mathrm{nC}_{5} * \mathrm{~S}_{\mathrm{k}}\right)$ is edgeodd graceful where $\mathrm{n}$ is any positive integer.

Proof: The graph has vertex set $\left\{\mathrm{V}_{0}, \mathrm{~V}_{1}, \mathrm{~V}_{2}, \mathrm{~V}_{3}, \mathrm{~V}_{4}, \mathrm{~V}_{5}, \mathrm{~V}_{6}\right.$, $\left.\mathrm{V}_{7}, \mathrm{~V}_{8}, \ldots, \mathrm{V}_{2 \mathrm{n}-3}, \mathrm{~V}_{2 \mathrm{n}-2}, \mathrm{~V}_{4 \mathrm{n}-1}, \mathrm{~V}_{4 \mathrm{n}}, \ldots, \mathrm{V}_{4 \mathrm{n}+1}, \mathrm{~V}_{4 \mathrm{n}+2}, \ldots, \mathrm{V}_{4 \mathrm{n}+\mathrm{K}}\right\}$ It has edge set $\left\{\mathrm{e}_{\mathrm{I}}=\mathrm{V}_{\mathrm{i}} \mathrm{V}_{\mathrm{i}+1}\right.$ : $\mathrm{i}$ varies from $\{1,2,3,5,6,7, \ldots, 4 \mathrm{n}$ $3,4 \mathrm{n}-2,4 \mathrm{n}-1\} \cup\left\{\mathrm{V}_{4} \mathrm{~V}_{0}, \mathrm{~V}_{8} \mathrm{~V}_{0}, \mathrm{~V}_{12} \mathrm{~V}_{0}, \ldots, \mathrm{V}_{4 \mathrm{n}} \mathrm{V}_{0}\right\} \cup\left\{\mathrm{V}_{0} \mathrm{~V}_{1}\right.$, $\left.\mathrm{V}_{4} \mathrm{~V}_{\mathrm{o}}, \mathrm{V}_{0} \mathrm{~V}_{5}, \mathrm{~V}_{8} \mathrm{~V}_{0}, \mathrm{~V}_{0} \mathrm{~V}_{9}, \mathrm{~V}_{12} \mathrm{~V}_{0}, \ldots, \mathrm{V}_{0} \mathrm{~V}_{4 \mathrm{n}-3}, \mathrm{~V}_{4 \mathrm{n}} \mathrm{V}_{0}\right\} \cup\{$ $\mathrm{V}_{0} \mathrm{~V}_{\mathrm{i}}$ : i varies from 1 to $\mathrm{k}$ \}. The arbitrary labelings of the edges for the given graph $\mathrm{FnC}_{5} * \mathrm{~S}_{\mathrm{k}}$ ) are as follows:

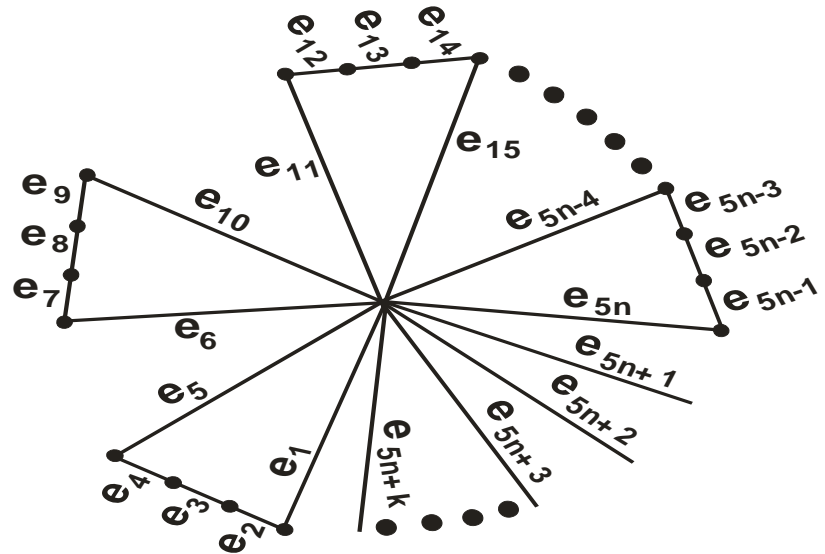

Figure 7: An arbitrary labelings of the friendship graph $\mathbf{F}\left(\mathrm{nC}_{5} * \mathbf{S}_{4}\right)$

Case (i) : $n$ is odd

Subcase (a): $k$ is even Define $f: E(G) \rightarrow\{1,3,5, \ldots 2 q-1\}$, by $f$ $\left(e_{i}\right)=(2 i-1), i=1$ to $5 n+k$.

Subcase (b): $k$ is odd Define $f: E(G) \rightarrow\{1,3,5, \ldots 2 q-1\}$ by $\mathrm{f}\left(\mathrm{e}_{\mathrm{i}}\right)=2 \mathrm{i}-1, \mathrm{i}=1$ to $5\left(\frac{n+1}{2}\right) ; 5 \mathrm{n}+1,5 \mathrm{n}+2, \ldots, 5 \mathrm{n}+\mathrm{k}$.

$$
\begin{array}{ll}
\mathrm{f}\left(\mathrm{e}_{\mathrm{i}}\right)=\mathrm{f}\left(\mathrm{e}_{5\left(\frac{\mathrm{n}+1}{2}\right)}\right)+2+4\left(\mathrm{i}-1-\frac{5(n+1)}{2}\right), & \mathrm{i}=\frac{5(n+1)}{2}+ \\
1, \ldots, \frac{15(n+1)}{4} & \\
\mathrm{f}\left(\mathrm{e}_{\mathrm{i}}\right)=\mathrm{f}\left(\mathrm{e}_{5\left(\frac{\mathrm{n}+1}{2}\right)}+4\right)+4\left(\mathrm{i}-1-\frac{15(n+1)}{4}\right) ; & \mathrm{i}=\frac{15(n+1)}{4} \\
+1, \ldots,(5 \mathrm{n}) . &
\end{array}
$$

Case (ii) $n$ is even

Subcase (c): Either $k$ is odd or $k$ is even with $k \geq n$ : Define $f$ $\left(e_{i}\right)=2 \mathrm{i}-1, \mathrm{i}=1$ to $5 \mathrm{n}+\mathrm{k}$.

Subcase $(\mathbf{d}) ; \mathrm{k}$ is even with $\mathrm{k}<\mathrm{n}$. Define $\mathrm{f}\left(\mathrm{e}_{\mathrm{i}}\right)=2 \mathrm{i}+1 ; \mathrm{i}=1$ to $5 \mathrm{n} / 2$;

$\mathrm{f}\left(\mathrm{e}_{\mathrm{i}}\right)=\mathrm{f}\left(\mathrm{e}_{5 n / 2}\right)+2+4\left(\mathrm{i}-1-\frac{15 n}{8}\right) ; \mathrm{i}=\frac{5 n}{2}+1, \ldots, \frac{15 n}{8} ; \mathrm{f}\left(\mathrm{e}_{\mathrm{i}}\right)$ $=\mathrm{f}\left(\left(\mathrm{e}_{5 n / 2}\right)+4\right)+4\left(\mathrm{i}-1-\frac{15 n}{8}\right) ; \mathrm{i}=\frac{15 n}{8}+1, \ldots, 5 \mathrm{n} ; \mathrm{f}\left(\mathrm{e}_{\mathrm{i}}\right)=$ $2 \mathrm{i}-1, \mathrm{i}=5 \mathrm{n}+1, \ldots, 5 \mathrm{n}(\mathrm{k}-1) ; \quad \mathrm{f}\left(\mathrm{e}_{5 \mathrm{n}+\mathrm{k}}\right)=1$.

In all cases, the induced map $\mathrm{f}^{+}(\mathrm{u})=\sum \mathrm{f}(\mathrm{uv}) \quad(\bmod 2 \mathrm{q})$ where the sum runs over all edges uv through $v$. Now, $f$ and $\mathrm{f}^{+}$ both satisfy edge-odd graceful labeling. Thus the connected graph $\mathrm{F}\left(\mathrm{nC}_{5} * \mathrm{~S}_{\mathrm{k}}\right)$ is an edge-odd graceful.

Example 3.2: The friendship graph $\mathrm{F}\left(5 \mathrm{C}_{5} * \mathrm{~S}_{4}\right)$ is edgeodd graceful.

The graph has $\mathrm{p}=25$ vertices, $\mathrm{q}=29$ edges. The edge-odd graceful labelings are mentioned below:

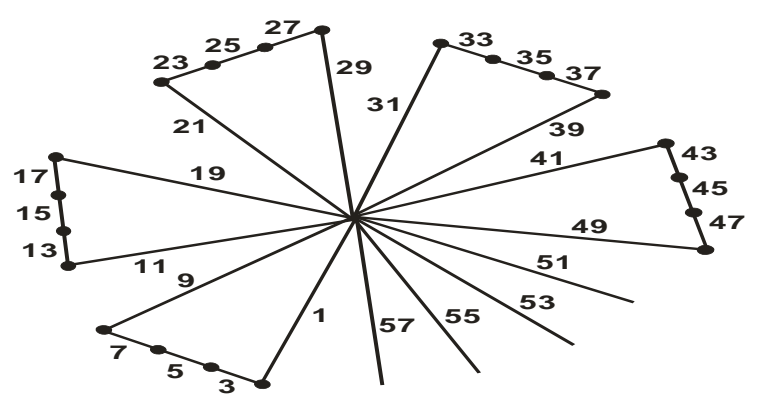

Figure 8: Edge-odd graceful of the friendship graph $\mathrm{F}\left(\mathrm{5C}_{5}\right.$ $\left.* \mathbf{S}_{4}\right)$

Example 3.3: The friendship graph $\mathrm{F}\left(4 \mathrm{C}_{5} * \mathrm{~S}_{3}\right)$ is edgeodd graceful.

The graph has $\mathrm{p}=21$ vertices, $\mathrm{q}=24$ edges. The edge-odd graceful labelings are mentioned below:

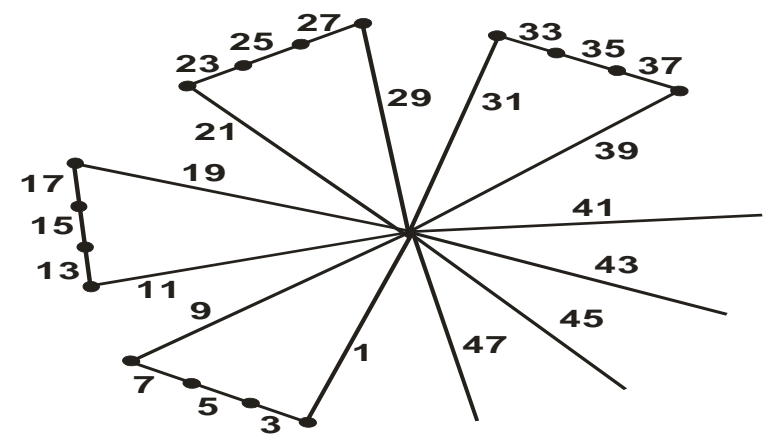

Figure 9: Edge-odd graceful of the friendship graph $\mathrm{F}\left(4 \mathrm{C}_{5}\right.$ $\left.* \mathbf{S}_{3}\right)$

Theorem 3.5 The friendship graph $\mathrm{F}\left(2 \mathrm{nC}_{3} * \mathrm{~S}_{\mathrm{k}}\right)$ is edgeodd graceful where $\mathrm{n}$ is any positive integer.

Proof: The graph has vertex set $\left\{\mathrm{V}_{0}, \mathrm{~V}_{1}, \mathrm{~V}_{2}, \mathrm{~V}_{3}, \mathrm{~V}_{4}, \mathrm{~V}_{5}\right.$, $\left.\mathrm{V}_{6}, \ldots, \mathrm{V}_{3 \mathrm{n}-2}, \mathrm{~V}_{3 \mathrm{n}-1}, \mathrm{~V}_{3 \mathrm{n}}, \mathrm{V}_{1}, \mathrm{~V}_{2}, \ldots, \mathrm{V}_{\mathrm{k}}\right\}$. It has edge set $\left\{\mathrm{V}_{0} \mathrm{~V}_{\mathrm{i}}: \mathrm{i}\right.$ varies from 1 to $3 \mathrm{n}+\mathrm{k}\} \cup\left\{\mathrm{V}_{\mathrm{i}} \mathrm{V}_{\mathrm{i}+1}\right.$ : $\mathrm{i}$ varies from 1 to $3 \mathrm{n}$ and $\mathrm{i}$ 
is not a multiple of 3$\}$. The arbitrary labelings of the edges or the given graph $\mathrm{F}\left(2 \mathrm{nC}_{3} * \mathrm{~S}_{\mathrm{k}}\right)$ are as follows:

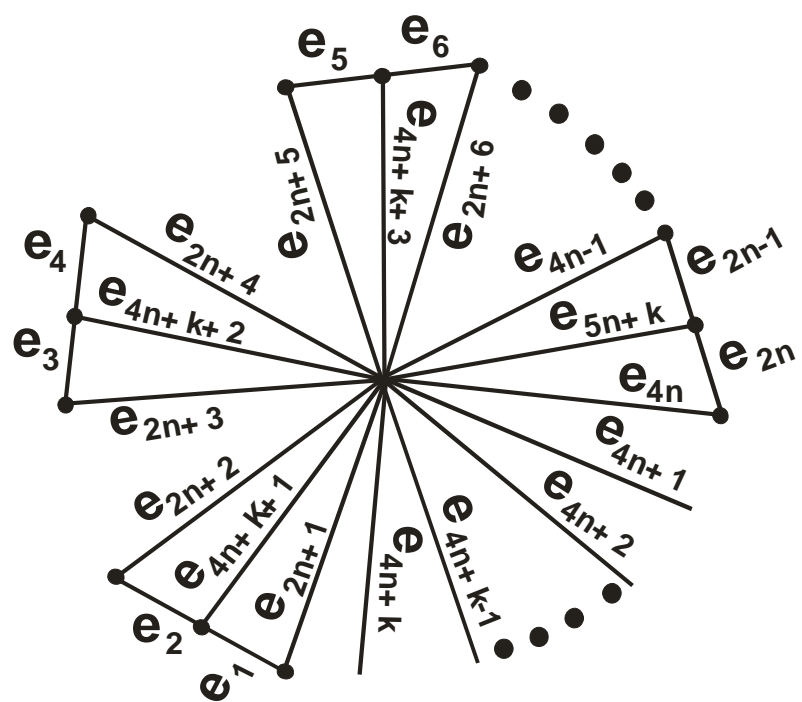

Figure 10: An arbitrary labelings of the friendship graph $\mathbf{F}\left(2 \mathrm{nC}_{3} * \mathrm{~S}_{\mathrm{k}}\right)$

Define $\mathrm{f}\left(\mathrm{e}_{\mathrm{i}}\right)=2 \mathrm{i}-1$, where $\mathrm{i}=1$ to $5 \mathrm{n}+\mathrm{k} ; \mathrm{i} \neq 1$, and $\mathrm{i} \neq 4 \mathrm{n}+\mathrm{k}$

Case (i): $\mathrm{n}$ is odd ; $\mathrm{k}$ is even $<\mathrm{n}$ : Define $\mathrm{f}\left(\mathrm{e}_{4 \mathrm{n}+\mathrm{k}}\right)=1 ; \mathrm{f}\left(\mathrm{e}_{1}\right)$ $=8 n+2 k-1$

Case (ii): All other cases: Define $\mathrm{f}\left(\mathrm{e}_{4 \mathrm{n}+\mathrm{k}}\right)=8 \mathrm{n}+2 \mathrm{k}-1$; $\mathrm{f}\left(\mathrm{e}_{1}\right)=$ 1

Then the induced map $\mathrm{f}^{+}(\mathrm{u})=\sum \mathrm{f}(\mathrm{uv}) \quad(\bmod 2 \mathrm{q})$ where the sum runs over all edges uv through $v$. Now, $f$ and $\mathrm{f}^{+}$both satisfy edge-odd graceful labeling. Thus the connected graph $\mathrm{F}\left(2 \mathrm{nC}_{3} * \mathrm{~S}_{\mathrm{k}}\right)$ is an edge-odd graceful.

Example 3.6: The friendship graph $\mathrm{F}\left(2.2 \mathrm{C}_{3} * \mathrm{~S}_{4}\right)$ is edge-odd graceful.

The graph has $p=17$ vertices, and $q=24$ edges. The edgeodd graceful labelings are mentioned below:

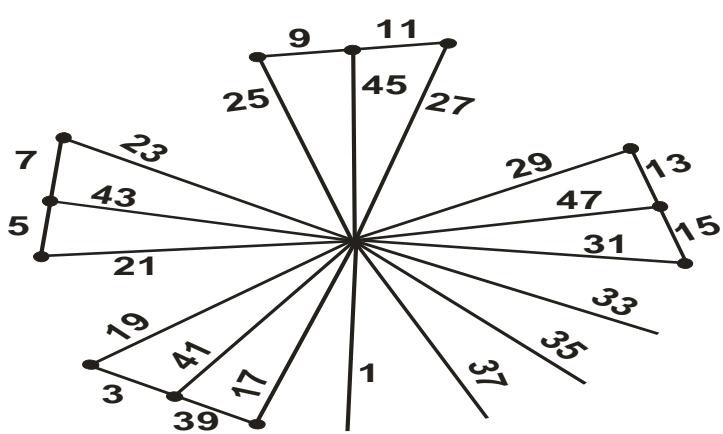

Figure 11: Edge-odd graceful of the friendship graph $\mathbf{F}\left(2.2 \mathrm{C}_{3} * \mathrm{~S}_{4}\right)$

\section{REFERENCES}

[1] A. Solairaju and K.Chitra, Edge-odd graceful labeling of some graphs, Electronics Notes in Discrete Mathematics Volume 33, April 2009, 15

[2] A. Solairaju and P.Muruganantham, even-edge gracefulness of ladder, The Global Journal of Applied Mathematics \& Mathematical Sciences(GJ-AMMS). Volume 1.Number 2, (July-December-2008):, 149-153.

[3] A. Solairaju and P.Muruganantham, even vertex gracefulness of path merging circuits, Indian Journal of Mathematics and Mathematical Sciences, Volume 6, Number 1, (June, 2010), $27-31$.

[4] A. Solairaju and P.Muruganantham, even vertex gracefulness of even number of copies of $\mathrm{C}_{4}$, accepted for publication in Serials Publications, New Delhi, India.

[5] A.Soliraju, and A.Sasikala, Gracefulness of a spanning tree of the graph of product of $\mathrm{Pm}_{\mathrm{m}}$ and ${ }_{\mathrm{Cn}}$, The Global Journal of Pure and Applied Mathematics of Mathematical Sciences, Volume 1, Number 2 (July-Dec 2008): 133-136

[6] A.Solairaju, and C.Vimala, Gracefulness of a spanning tree of the graph of Cartesian product of $S_{m}$ and $S_{n}$, The Global Journal of Pure and Applied Mathematics of Mathematical Sciences, Volume 1, Number 2 (July-Dec 2008): 117-120. 